\title{
AVALIAÇÃO DO ESTADO NUTRICIONAL DE CRIANÇAS MENORES DE CINCO ANOS DO ESTADO DE RONDÔNIA - BRASIL*
}

\author{
Haroldo da Silva Ferreira* \\ Ari Miguel Teixeira $\mathrm{Ott}^{* * *}$
}

\begin{abstract}
FERREIRA, H. da S. \& OTT, A. M. T. Avaliação do estado nutricional de crianças menores de cinco anos do Estado de Rondônia - Brasil. Rev. Saúde públ., S. Paulo, 22: 179 - 83, 1988.

RESUMO: Com o objetivo de se conhecer a prevalência e as formas de desnutrição protéicocalórica entre os pré-escolares dos municípios da área de atuação do programa Polonoroeste no Estado de Rondônia, Brasil, procedeu-se a uma avaliação antropométrica entre os menores de cinco anos presentes no momento da entrevista em domicilios sorteados. Foram estudadas 1.274 crianças, sendo a amostra representativa das zonas lirbanas dos munićpios de Ariquemes e Ji-Paraná e da área rural de Ouro Preto D'Oeste. Através da classificação de Gomez, encontrou-se cerca de 31,9\% com desnutrição leve e 4,8\% nas formas moderada e grave. A classificação de Waterlow revelou que $6,0 \%$ apresentava desnutrição aguda e $0,2 \%$ desnutrição crônica.
\end{abstract}

UNITERMOS: Estado nutricional. Estudo de avaliação. Desnutrição protéico-calórica. Criança, préescolar

\section{INTRODUÇÃO}

Em crianças, a deficiência de calorias e proteínas tem, freqüentemente, como primeira manifestação, o déficit de peso. Os sinais clínicos na desnutrição protéico-calórica (DPC) só ocorrem tardiamente e, portanto, nos casos mais severos. Segundo Waterlow ${ }^{10}$, "os dados antropométricos são os mais sensíveis, objetivos e quantificáveis para descrever a DPC em crianças em crescimento. Os estudos alimentares são dificilmente comparáveis, devido à variedade de métodos utilizados. A validade dos dados clínicos é discutivel, pois se caracterizam por difícil quantificação e comparabilidade". Quanto aos dados bioquímicos ${ }^{8}$, estes necessitam de infra-estrutura de laboratório, pois há dificuldades na coleta, armazenamento e transporte de amostras, exigindo maior treinamento dos entrevistadores.

A alimentação inadequada nos primeiros anos de vida pode conduzir a criança a um estado de desnutrição, caraterizado pelo crescimento abaixo do esperado, peso deficiente ou ambas as situaçôes combinadas. Assim, restrições alimentares agudas terão reflexos imediatos sobre o peso, enquanto observaçōes de déficits na estatura só serão possíveis caso essa restriçăo seja prolongada. Por esse motivo, o peso é um dos indicadores mais sensíveis para diagnosticar desnutriçăo, sendo que observaçōes de déficits ponderais podem indicar desnutrição recente ou atual, enquanto déficits na altura podem estar relacionados a uma desnutriçăo pregressa. No caso do indivíduo apresentar deficiência ponderal e estatural, pode-se estar frente a um caso de desnutrição crônica, ou seja, do passado até o presente. Conseqüentemente, na avaliação do estado nutricional de populações é importante a utilização de indicadores que mostrem a prevalência da DPC.e as formas pelas quais se apresentam.

De acordo com Monteiro6, estão disponíveis atualmente dois padrões de referência que atendem aos requisitos do que seriam os "padrōes de normalidade": padrão de Santo André classe IV e o do National Center for Health Statistics (NCHS). A World Health Organization (WHO) ${ }^{7}$ a nível internacional, e o Instituto Nacional de Alimentação e Nutrição (INAN/MS) ${ }^{5}$ e o Ministério da Previdência e Assistência Social (MPAS) $^{4.5}$, no Brasil, utilizam o padrão do NCHS.

A inexistência de estudos anteriores que demonstrassem a prevalência e severidade da DPC

* Parte do projeto "Diagnóstico das Condições de Saúde em Rondônia", realizado com recursos financeiros do Programa Integrado de Desenvolvimento do Noroeste do Brasil (POLONOROESTE). Apresentado no XI Congresso Brasileiro de Nutrição, Salvador, 1987.

* Hospital Universitário e Departamento de Nutrição da Universidade Federal de Alagoas - Campus Universitário - 57000 - Maceí, AL - Brasil.

*** Departamento de Ciências Biomédicas da Fundação Universidade Federal de Rondônia - Av. Presidente Dutra, 2965 - 78900 - Porto Velho, RO - Brasil. 
na população pré-escolar dos municípios de abrangência do Programa Integrado de Desenvolvimento do Noroeste do Brasil (POLONOROESTE) e a importância desse conhecimento para as atividades de planejamento de programas governamentais, levaram-nos a desenvolver a presente investigação.

Considerando-se os aspectos operacionais e os recursos humanos e financeiros existentes para essa pesquisa, levou-nos a eleger os dados antropométricos (peso e altura) como indicadores para a avaliação do estado nutricional dos préescolares de Rondônia.

\section{MATERIAL E MÉTODOS}

Foram avaliadas 1.274 crianças de 0 a 60 meses de idade, empregando-se a classificação de Gomez. Desse total, 1.259 criaças foram também avaliadas através da classificação de Warterlow ${ }^{10}$, considerando desnutrido quem apresentasse adequação inferior a $80 \%$ e $90 \%$ para os indicadores peso por altura e altura por idade, respectivamente. $O$ padrão antropométrico de referência adotado foi o proposto pelo NCHS.

O Plano amostral estabeleceu que as áreas urbanas de Ji-Paraná e Ariquemes e rural de Ouro Preto D'Oeste seriam auto-representativas, isto é, selecionados com probabilidade 1. Para cada uma dessas áreas urbanas decidiu-se estabelecer uma amostragem em dois estágios, com fração amostral total e probabilidade proporcional ao tamanho. Para as áreas urbanas definiu-se a quadra (conjunto com num mínimo 70 e no máximo 110 domicílios), como unidade amostral de primeiro estágio e o domicilio como unidade de segundo estágio. Para a área rural, a unidade amostral de primeiro estágio foi a linha (estrada que, avançando mata a dentro, permite o acesso e delimita cerca de 200 lotes), enquanto para unidade de segundo estágio tomou-se o lote.
Em função do número total de domicnlios estimado para 1984, de algumas variáveis de estudo na pesquisa e a disponibilidade de recursos humanos e financeiros, decidiu-se tomar uma fração amostral total igual a $10 \%$ dos domicílios nas áreas urbanas de Ariquemes e Ji-Paraná. Para a área rural, levando-se em conta as características especiais do trabalho de campo em florestas, a fração amostral foi reduzida para $7,5 \%$ dos lotes do Projeto Integrado de Colonização Ouro Preto. As quadras/domicilios e linhas/lotes foram selecionadas através de sorteio casual para uma amostragem sistemática. No entanto, os problemas inerentes aos procedimentos de campo (recusas, domicílios fechados ou inalcançável, etc) reduziram a fraçăo amostral para $8,2 \%$ em Ariquemes, $8,3 \%$ em Ji-Paraná e $5,2 \%$ em Ouro Preto D'Oeste, equivalendo respectivamente a 422, 854 e 426 domicílios.

Para cada domicílio sorteado foram estudadas todas as crianças menores de 5 anos presentes no momento da entrevista. Eram coletados os dados de peso, estatura e idade e anotados em formulário próprio por entrevistadores previamente treinados e padronizados (Método de Gouveia) ${ }^{3}$.

Para a tomada de peso foi utilizada balança de gancho, tipo "palanca", com capacidade para 20 quilos; para a altura em crianças maiores de 2 anos foi utilizado metro dobrável de madeira tipo "metro de carpinteiro" e esquadro metálico; para as crianças menores utilizou-se régua antrométrica com lâminas fixas e móvel.

\section{RESULTADOS}

Os resultados referentes a 1.274 crianças avaliadas pela classificação de Gomez estão expressos na Tabela 1, enquanto a Tabela 2 apresenta os resultados da avaliaçăo de 1.259 crianças pela classificação de Waterlow. Observa-se que a zona rural aparece com freqüências de desnutriçăo maiores

\section{TABELA 1}

Distribuição do estado nutricional, através da classificação de Gomez, de crianças de 0 a 60 meses, nos municípios de Ariquemes, Ouro Preto D'Oeste e Ji-Paraná, Rondônia, Brasil-1985

\begin{tabular}{|c|c|c|c|c|c|c|c|c|}
\hline \multirow{2}{*}{$\begin{array}{l}\text { Estado } \\
\text { Nutricional }\end{array}$} & \multicolumn{2}{|c|}{ Ariquemes } & \multicolumn{2}{|c|}{ Ji-Paraná } & \multicolumn{2}{|c|}{ Ouro Preto D'Oeste } & \multicolumn{2}{|c|}{ Total } \\
\hline & $\mathrm{N}^{\mathrm{e}}$ & $\%$ & No & $\%$ & $N^{2}$ & $\%$ & Ne & $\%$ \\
\hline $\begin{array}{l}\text { Normal } \\
\text { Obeso } \\
\text { Desnutriçăo I } \\
\text { Desnutrição II } \\
\text { Desnutrição III }\end{array}$ & $\begin{array}{r}151 \\
33 \\
93 \\
13 \\
1\end{array}$ & $\begin{array}{r}51,9 \\
11,3 \\
32,0 \\
4,5 \\
0,3\end{array}$ & $\begin{array}{r}307 \\
93 \\
174 \\
15 \\
2\end{array}$ & $\begin{array}{r}52,0 \\
15,7 \\
29,4 \\
2,5 \\
0,4\end{array}$ & $\begin{array}{r}173 \\
50 \\
139 \\
28 \\
2\end{array}$ & $\begin{array}{r}44,1 \\
12,8 \\
35,5 \\
7,1 \\
0,5\end{array}$ & $\begin{array}{r}631 \\
176 \\
406 \\
56 \\
5\end{array}$ & $\begin{array}{r}49,5 \\
13,8 \\
31,9 \\
4,4 \\
0,4\end{array}$ \\
\hline Total & 291 & 100,0 & 591 & 100,0 & 392 & 100,0 & 1274 & 100,0 \\
\hline
\end{tabular}


TABELA 2

Distribuiçăo do estado nutricional, através da classificaçāo de Waterlow, de crianças de 0 a 60 meses, nos minicípios de Ariquemes, Ouro Preto D'Oeste e Ji- Paraná, Rondônia, Brasil-1985.

\begin{tabular}{|c|c|c|c|c|c|c|c|c|}
\hline \multirow{2}{*}{$\begin{array}{l}\text { Estado } \\
\text { Nutricional }\end{array}$} & \multicolumn{2}{|c|}{ Ariquemes } & \multicolumn{2}{|c|}{ Ji-Paraná } & \multicolumn{2}{|c|}{ Ouro Preto D'Oeste } & \multicolumn{2}{|c|}{ Total } \\
\hline & $\mathrm{N}^{2}$ & $\%$ & $\mathrm{~N}^{2}$ & $\%$ & $N^{2}$ & $\%$ & $\mathrm{~N}^{2}$ & $\%$ \\
\hline $\begin{array}{l}\text { Eutrofia } \\
\text { Desnutrição Aguda } \\
\text { Desnutrição Pregressa } \\
\text { Desnutrição Crốnica }\end{array}$ & $\begin{array}{r}256 \\
5 \\
21 \\
-\end{array}$ & $\begin{array}{r}90,8 \\
1,8 \\
7,4 \\
-\end{array}$ & $\begin{array}{r}552 \\
9 \\
31 \\
-\end{array}$ & $\begin{array}{r}93,2 \\
1,5 \\
5,2 \\
-\end{array}$ & $\begin{array}{r}335 \\
24 \\
24 \\
2\end{array}$ & $\begin{array}{r}87,8 \\
62 \\
6,2 \\
0,6\end{array}$ & $\begin{array}{r}1.143 \\
38 \\
76 \\
2\end{array}$ & $\begin{array}{r}90,8 \\
3,0 \\
6,0 \\
0,2\end{array}$ \\
\hline Total & 282 & 100,0 & 592 & 100,0 & 385 & 100,0 & 1259 & 100,0 \\
\hline
\end{tabular}

do que as áreas urbanas, e estas, por sua vez, apresentam-se com taxas maiores para a cidade que tem um menor desenvolvimento urbano, no caso Ariquemes. As diferenças observadas são estatisticamente significativas quando testadas pelo qui quadrado.

A Tabela 3 apresenta o cruzamento entre o estado nutricional e a renda familiar, representada pelo número de salários mínimos (SM). Infeliz- mente, em função do alto número de nãoresposta para esse item, não foi possível computar essa informação para a zona rural. Nas áreas urbanas, de 882 famílias entrevistadas, 351 $(39,8 \%)$ não responderam sobre a questão da renda.

Ainda assim é possível verificar que a prevalência de DPC é inversamente proporcional à renda familiar, embora tenha havido maior pre-

TABELA 3

Distribuição do estado nutricional (Gomez) entre as crianças de 0 a 60 meses segundo a renda familiar. Ariquemes e ji-Paraná, Rondônia, Brasil - 1985.

\begin{tabular}{|c|c|c|c|c|c|c|c|c|c|c|}
\hline \multirow[t]{2}{*}{$\begin{array}{l}\text { Estado } \\
\text { Nutricional }\end{array}$} & \multicolumn{10}{|c|}{ Renda } \\
\hline & $\mathrm{N}^{2}$ & $\%$ & $\mathrm{~N}^{2}$ & $\%$ & $N^{2}$ & $\%$ & $N^{2}$ & $\%$ & $\mathrm{~N}^{2}$ & $\%$ \\
\hline $\begin{array}{l}\text { Normal } \\
\text { Obeso } \\
\text { Desnutrição I } \\
\text { Desnutrição II }\end{array}$ & $\begin{array}{r}185 \\
43 \\
120 \\
12\end{array}$ & $\begin{array}{c}51,4 \\
11,9 \\
33,3 \\
3,3\end{array}$ & $\begin{array}{c}54 \\
21 \\
18 \\
2\end{array}$ & $\begin{array}{r}56,8 \\
22,1 \\
19,0 \\
2,1\end{array}$ & $\begin{array}{r}20 \\
8 \\
11 \\
1\end{array}$ & $\begin{array}{r}50,0 \\
20,0 \\
27,5 \\
2,5\end{array}$ & $\begin{array}{r}21 \\
12 \\
3 \\
-\end{array}$ & $\begin{array}{c}58,3 \\
33,3 \\
8,3 \\
-\end{array}$ & $\begin{array}{r}280 \\
84 \\
152 \\
15\end{array}$ & $\begin{array}{r}52,7 \\
15,8 \\
28,6 \\
2,8\end{array}$ \\
\hline Total & 360 & 100,0 & 95 & 100,00 & 40 & 100,0 & 36 & 100,0 & 531 & 100,0 \\
\hline
\end{tabular}

SM: Salário Mínimo

$$
X^{2}=26,48
$$

valência na categoria de 7 a $10 \mathrm{SM}$ em relaçăo à de 4 a 7 SM.

Não houve preocupação em analisar as eventuais associaçōes entre DPC e outras variáveis, dado que acreditamos ser a renda familiar a determinante última de outras características comumente analisadas como escolaridade, assistência médica, habitação, saneamento, além de outras.

\section{DISCUSSÃO}

Em termos genéricos não se encontrou nenhum dado não explicado. A população da
$X^{2}$ crítico $=21,66 \quad(p<0,01)$

zona rural está, pelas próprias condições de vida, mais exposta à inadequação alimentar, além de, eventualmente, ser expoliada por doenças parasitárias concomitantes. Nas áreas urbanas, a melhor situação de Ji- Paraná, comparativamente com Ariquemes, pode ser explicado pelo fato de que aquele município é um dos três mais antigos de Rondônia, com melhor definição econômica $e$ urbanística, ao contrário deste que é um município novo tentando estruturar- se.

Para a associação entre DPC e nível de renda, deve-se discutir a inversão nos dados de desnutrição do I grau e obesidade para as crianças de famílias com renda entre 4 e $7 \mathrm{SM}$ e as de renda 
entre 7 e $10 \mathrm{SM}$. Isto é, há mais desnutridos e menos obesos, percentualmente, na faixa de renda mais alta. Pode-se estar frente a uma situação na qual as pessoas estariam investindo mais em bens de consumo, por não resistirem ao apelo do consumismo, em detrimento de um padrão alimentar adequado na faixa de renda mais alta. Por outro lado, entre as pessoas de renda mais baixa, o investimento em uma melhor alimentação se daria por absoluta impossibilidade de acesso ao mercado de bens de consumo.

Embora apareça em percentuais menores do que a desnutrição, a obesidade deve ser objeto de preocupação. No Brasil, a obesidade tem recebido pouca atenção, talvez porque a desnutrição é um grave problema. Para os países desenvolvidos, esta condição é reconhecida como problema de saúde pública. Como o Brasil apresenta em suas estatísticas de morbi-mortalidade condiçōes típicas do subdesenvolvimento, ao lado de doenças características do desenvolvimento capitalista, é importante que os estudos de avaliação nutricional de populaçóes apresentem os resultados de obesidade e eutrofia separados e não consolidados na categoria de normal. Ainda mais porque é reconhecida a importância da fase de crescimento na determinação do número total de adipócitos ${ }^{2}$. Assim procedendo, poder-se-ia re- unir um melhor acervo de informaçðes relativas à obesidade.

Os resultados da presente pesquisa mostram-se críticos, mas não alarmantes, quando os comparamos a outros estudos como o do ENDEF (citado por Albuquerque ${ }^{1}$ ) e o inquérito nutricional realizado na cidade de Jauru1 (Tabela 4).

A prevalência geral de DPC encontrada para Rondônia foi menor do que para o Nordeste e Jauru, havendo uma semelhança com o dados do Rio de Janeiro e São Paulo (Tabela 4).

Cabe ainda ressaltar que, embora os três estudos apresentados na Tabela 4 tenham sido efetuados em pré-escolares, cada um utilizou uma faixa etária específica: 12 a 59 meses; 3 a 72 meses e 0 a 60 meses. Quanto ao padrão antropométrico houve concordância entre Rondônia e Jauru (NCHS), enquanto o ENDEF utilizou o padrão de Harvard. Acreditamos que, apesar das diferenças metodológicas, são válidas as comparaçőes. Eventuais erros poderão ser explicados em funçăo da representatividade das respectivas amostras, o que só seria confirmado através de estudos subseqüentes.

$\mathrm{Na}$ comparação entre estes mesmos estudos,

TABELA 4

Comparação entre o estado nutricional, segundo Gomez, de crianças de 12 a 59 meses do Nordeste, Rio de Janeiro e São Paulo (ENDEF); e crianças de 0 a 60 meses de Rondônia.

\begin{tabular}{lccccc}
\hline & \multicolumn{5}{c}{ Região } \\
\cline { 2 - 6 } \multicolumn{1}{c}{ Nutrado } & $\mathrm{NE}^{*}$ & $\mathrm{RJ}$ & $\mathrm{SP}$ & Jauru & Rondônia ** \\
\hline Normal & 37,6 & 60,3 & 59,8 & 19,3 & 63,3 \\
Desnutriçăo I & 40,6 & 31,7 & 33,4 & 62,6 & 31,9 \\
Desnutrição II & 17,9 & 72 & 6,1 & 18,1 & 4,4 \\
Desnutriçăo III & 3,8 & - & - & - & 0,4 \\
\hline
\end{tabular}

Fonte: Albuquerque ${ }^{1}$ (1984) excetuando Rondônia

* NE (Nordeste); RJ (Rio de Janeiro); SP (São Paulo)

* Rondônia representa os dados dos três municípios consolidados

\section{TABELA 5}

Comparação entre o estado nutricional, segundo Waterlow, de crianças de 12 a 59 meses do Nordeste, Rio de Janeiro e São Paulo (ENDEF); crianças de 3 a 72 meses de Jauru (UFMT) e crianças de 0 a 60 meses de Rondônia.

\begin{tabular}{lccccc}
\hline & \multicolumn{5}{c}{ Região } \\
\cline { 2 - 6 } \multicolumn{1}{c}{ Estado } & $\mathrm{NE}^{*}$ & $\mathrm{RJ}^{*}$ & $\mathrm{SP}$ & Jauru & Rondônia $^{* *}$ \\
\hline Eutrofia & 57,3 & 72,0 & 76,9 & 66,2 & 90,8 \\
Desnutriçăo pregressa & 24,9 & 9,7 & 8,9 & 4,9 & 3,0 \\
Desnutriçăo aguda & 10,9 & 15,2 & 11,8 & 25,4 & 3,0 \\
Desnutriçăo crônica & 6,9 & - & - & 3,5 & 0,2 \\
\hline
\end{tabular}

Fonte : Albuquerque ${ }^{1}$ (1984) excluindo Rondônia

- NE (Nordeste); RJ (Rio de Janeiro); SP (São Paulo)

** Rondônia representa os dados dos três municípios consolidados 
agora através da classificaçăo de Waterlow (Tabela 5), observa-se que na amostra de Rondônia não houve alta prevalência em nenhuma das formas de DPC, principalmente em termos de desnutrição aguda e crônica.

Devemos observar que os limites da classificação de Waterlow foram definidos levando-se em consideração a necessidade de intervenção. Por esta razão, privilegiou a especificidade em detrimento da sensibilidade, já que estas são inversamente proporcionais, ou seja, à medida que se aumenta o limite (tolerância) da normalidade, diminui a possibilidade de atribuir desnutrição a sadios (falsos positivos) obtendo-se assim maior especificidade. Inversamente a possibilidade de deixar de diagnosticar indivíduos realmente desnutridos (falsos negativos) torna-se mais elevada, resultando baixa sensibilidade. Deste modo, seria pertinente a aplicacação da classificaçåo de Seoane e Lathan ${ }^{9}$ que, utilizando os mesmos indicadores da classificaçăo de Waterlow, mas possuindo uma menor "tolerância" para a normalidade, apresenta maior sensibilidade e por isso seja, talvez, mais recomendada a estudos de prevalência.

A análise dos resultados obtidos neste estudo, em comparação aos apresentados nas Tabelas $4 \mathrm{e}$ 5 , leva à conclusão de que o consumo alimentar na população pré-escolar pesquisada, vem se procedendo a um nível de adequação inferior às necessidades nutricionais para um perfeito crescimento e desenvolvimento, resultando em uma forma insidiosa de desnutrição. Mas, pelo fato de que a regiåo năo sofre períodos críticos em disponibilidade de alimentos, como ocorre, por exemplo, em áreas nordestinas à época das secas, prossegue sem evoluir para um agravamento, passando despercebida pelos governantes e impondo grandes prejuízos à população.

\section{AGRADECIMENTOS}

Ao Professor Odécio Sanches, da Escola de Enfermagem de Ribeirão Preto, por sua assessoria na definiçăo do plano amostral, e à Professora Eliete Salomon Tudisco, da Escola Paulista de Medicina, por sua contribuição no planejamento metodologico.

FERREIRA, H. da S. \& OTT, A. M. T. [Evaluation of nutritional state of children under the age of five in three localities in Rondônia, Brazil.] Rev. Saúde públ, S. Paulo, 22: $179-83$, 1988.

ABSTRACT: With the objective of discovering the prevalence and the kinds of protein energy malnutrition (PEM) among children under the age of five, in the State of Rondônia, anthropometric evaluation was made. About 1,274 children were studied and this sample represents the urban-area of Ariquemes and Ji-Parana and the rural area of Ouro Preto D'Oeste. The prevalence of PEM encountered (Gomez) was $31.9 \%$ and of these, $4.8 \%$ were of 2 nd or 3 rd degree. By means of Waterlow's classification, $6.0 \%$ were found to have had malnutrition in the past $3.0 \%$ recent malnutrition and $0.2 \%$ chronic malnutrition.

UNITERMS: Nutritional status. Evaluation studies. Protein-calorie malnutrition. Child, preschool.

\section{REFERÊNCIAS BIBLIOGRÁFICAS}

1. ALBUQUERQUE, M. C. W. et al. Inquérito nutricional em Jauru-MT. Universidade, Cuiabá, 3: 109-35, 1984.

2. BURTON, B. T. Obesidade e magreza. In: Burton, B. T. Nutriçąo humana. São Paulo, Mc Graw-Hill do Brasil, 1979. p. 253-72.

3. GOUVEIA, E. L. C. Diagnóstico do estado nutricional da população. In: Chaves, N. Nutriçăo: básica e aplicada. Rio de Janeiro, Editora Guanabara Koogan, 1978. p. 245-74.

4. MINISTERIO DA PREVIDÊNCIA E ASSISTENCLIA SOCIAL. Manual para avaliagéo antropométrica do estado nutricional de crianças ate 7 anos de idade. Brasilia, 1983.

5. MINISTERIO DA SAÚDE/MINISTERIO DA PREVIDENCIA E ASSISTENCIA SOCIAL. Acompanhamento do crescimento e desenvolvimento: manual. Braslia, 1984.

6. MONTEIRO, C. A. Critérios antropométricos no diagnóstioo da desnutriçăo em programas de assistência à criança. Rev. Saúde públ., S. Paulo, 18: 209-17. 1984.

7. ORGANIZACION MUNDIAL DE LA SALUD. Medición del cambio del estado nutricional. Ginebra, 1983.

8. OTT, A. M. T. et al. Diagnóstico das condiçōes de saúde em Rondônia: programa Polonoroeste/Secretaria de Estado da Saude. Porto Velho, 1985. [Mimeografado]

9. SEOANE, N. \& LATHAN, M. C. Nutritional anthropometry in the identification of malnutrition in childhood. J. Pediat. Environ. Child Hith, 17: 98-103, 1971.

10. WATEELOW, J. C. et al. The presentation and use of height and weight data for comparing the nutritional status of groups of children under the age of 10 year. Bull.Wld Hith Org.,55: 489- 98, 1977.

Recebido para publicaçăo em 26/6/1987 Reapresentado em 30/11/1987 Aprovado para publicagáo em 2/12/1987 